\title{
Cough and Asthma
}

\author{
Akio Niimi* \\ Department of Respiratory Medicine, Graduate School of Medicine, Kyoto University, Kyoto 606-8507, Japan
}

\begin{abstract}
Cough is the most common complaint for which patients seek medical attention. Cough variant asthma (CVA) is a form of asthma, which presents solely with cough. CVA is one of the most common causes of chronic cough. More importantly, 30 to $40 \%$ of adult patients with CVA, unless adequately treated, may progress to classic asthma. CVA shares a number of pathophysiological features with classic asthma such as atopy, airway hyper-responsiveness, eosinophilic airway inflammation and various features of airway remodeling. Inhaled corticosteroids remain the most important form of treatment of CVA as they improve cough and reduce the risk of progression to classic asthma most likely through their prevention of airway remodeling and chronic airflow obstruction.
\end{abstract}

Keywords: Chronic cough, eosinophils, asthma, cough variant asthma, airway inflammation, inhaled corticosteroid.

\section{INTRODUCTION}

Cough is a very common complaint for which patients seek medical attention [1, 2]. A number of guidelines defined chronic cough as cough lasting for 8 weeks or longer $[1,3-5]$. As such, chronic cough can lead to impaired quality of life [6]. Asthma is a disease in which the airways narrow excessively in response to various stimuli in the presence of airway hyper-responsiveness (AHR) and eosinophilic airway inflammation. In "classic asthma" (CA) variable airflow obstruction typically leads to symptoms such as wheeze, dyspnea and cough. In 'variant asthma' originally described by Glauser in 1972 [7] and subsequently re-named, by Corrao et al. [8] as 'cough variant asthma' (CVA) cough can be the sole presenting symptom. CVA remains one of the commonest causes of chronic cough worldwide [2,9]. More importantly, in CA cough may be associated with worse prognosis [10-12]. This review article will discuss various subtypes of asthma and associated eosinophilic airway disorders such as CVA, non-asthmatic eosinophilic bronchitis (NAEB); originally termed eosinophilic bronchitis without asthma and atopic cough [13-19].

\section{COUGH AND ASTHMA}

Cough is a major symptom of asthma. Cough in asthma can be classified into three categories CVA, coughpredominant asthma and cough that persists despite standard therapy with inhaled corticosteroids and bronchodilators [19, 20]. CVA is a subtype of asthma that usually presents solely with cough without any other symptoms such as dyspnea or wheezing [8]. In cough-predominant asthma cough is the most predominant symptom but other symptoms are also present such as dyspnea and/or wheeze [19-21]. These symptoms can be elicited on careful clinical history and examination. The third subtype is defined as cough that persists despite the control of other symptoms such as wheeze and breathlessness with standard treatment such as

*Address correspondence to this author at the Department of Respiratory Medicine, Graduate School of Medicine, Kyoto University, Sakyo-ku, Kyoto 606-8507, Japan; Tel: 81-75-751-3830; Fax: 81-75-751-4643;

E-mail: niimi@kuhp.kyoto-u.ac.jp inhaled corticosteroids (ICS) and beta-agonists. There are two subtypes in this category. In the first subtype cough is responsive to anti-mediator drugs such as leukotriene receptor antagonists, histamine $\mathrm{H} 1$ receptor antagonists and thromboxane synthesis inhibitors or receptor antagonists. The inflammatory mediators blocked by these agents are likely involved in the development of cough [22, 23]. Cough in this subtype is considered a manifestation of asthma, which is refractory to ICS and bronchodilators. The other subtype is cough due to concomitant conditions such as gastroesophageal reflux disease (GERD). Co-existence of GERD with asthma or CVA is fairly common, and cough may subside with anti-reflux medications [24]. Such phenomena may be explained by "cough-reflux selfperpetuating positive feedback cycle" leading to vicious cycle of cough and reflux [25]. As subjective measures of cough (cough scores and visual analogue scale) and cough reflex sensitivity are poor surrogates for objective cough frequency and cough-related quality of life assessment may be more appropriate when assessing cough [26].

\section{MUCUS HYPER-SECRETION IN ASTHMA AND CHRONIC COUGH}

Cough in asthma is typically dry or minimally productive, but it may also be associated with hypersecretion of mucus. Mucus hyper-secretion in asthma may be potentially related with steeper decline of pulmonary function [27] and fatal disease [28]. Measurement of secreted mucin in sputum has been reported in asthma [29], but not in chronic cough, which may involve goblet cell hyperplasia of bronchial epithelium with variable sputum production [30, 31]. We conducted a cross-sectional study to examine mucin levels of induced sputum supernatant in 49 patients with CA, 53 with chronic cough (39 with CVA, 9 with sinobronchial syndrome, 5 with GERD) and 11 healthy subjects [32]. Sinobronchial syndrome (SBS) was defined as chronic sinusitis complicated by neutrophilic inflammation of the lower airways [2]. An ELISA method was used [32] to detect total levels of various types of airway mucin such as MUC5AC and MUC5B [29]. Sputum symptom was semiquantified by using a questionnaire. Sputum production was more prevalent in patients with CA, CVA, or SBS than in 


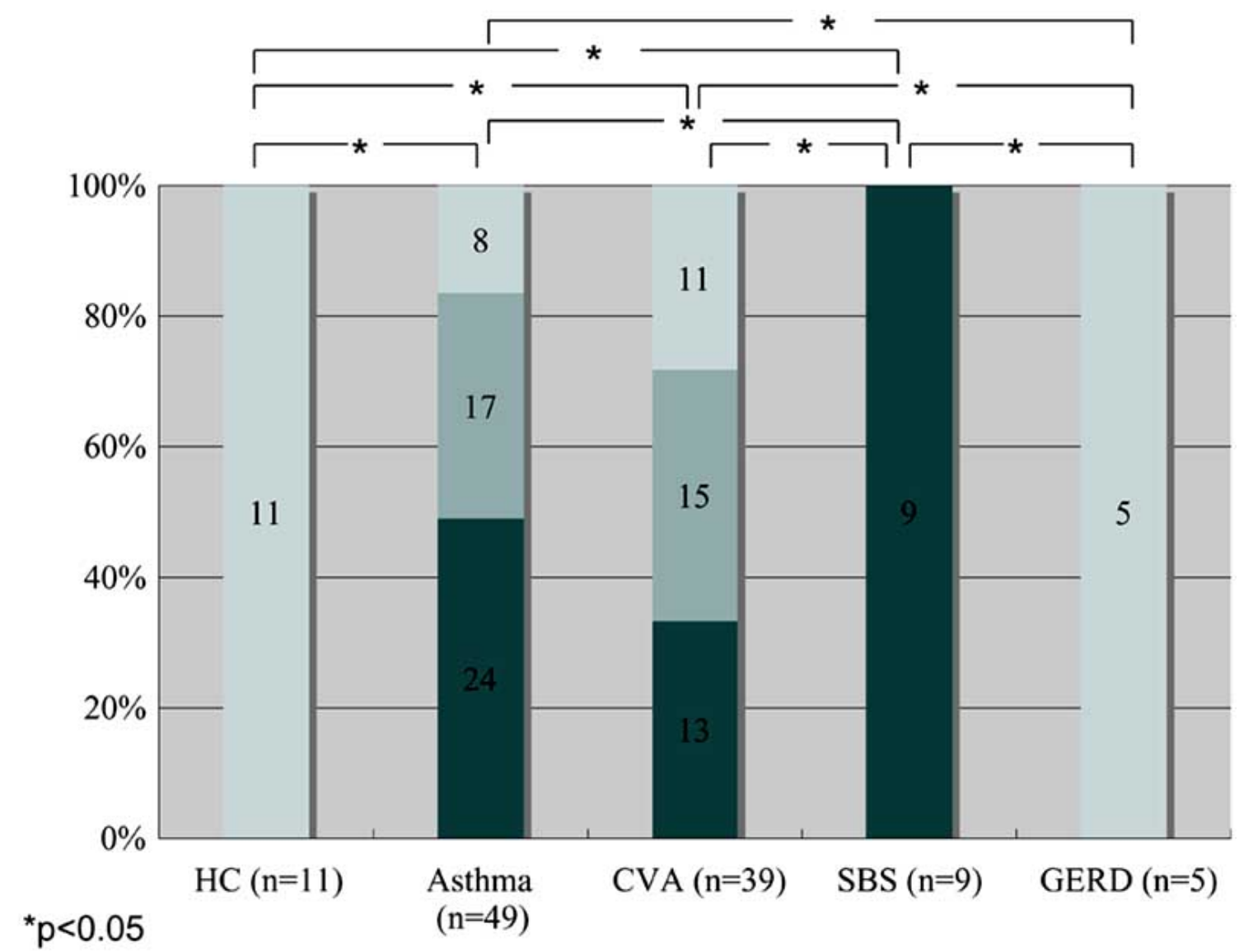

\section{Frequent $\square$ Occasional $\amalg$ Nil}

Fig. (1). Frequency of sputum symptom in patients with asthma and chronic cough of various causes, who succeeded in sputum induction for measurement of mucin in the supernatant (ref. [32]). CVA=cough variant asthma; SBS=sinobronchial syndrome; GERD=gastroesophageal reflux disease.

those with GERD and the controls. Whilst all SBS patients complained of frequent sputum production, none of the GERD patients reported sputum production, resulting in statistical differences for these two groups when compared with other disease groups (Fig. 1) [32]. Notably, 13 of 39 CVA patients reported frequent sputum production. This may not be a true reflection of the clinical features of CVA, because only patients that succeeded with sputum induction were enrolled, possible resulting in selection bias [33]. However, it is important to notice that a subset of patients with CVA presents with productive cough. Sputum mucin levels were higher in CA and SBS than in the controls. They were also higher in CA than in CVA and GERD, but not different among the latter groups and the controls (Fig. 2) [32]. When the four disease groups were combined, patients with frequent sputum production had greater mucin levels than those with occasional or no sputum production, or controls (Fig. 3) [32]. These results indicated that the difference in mucin levels among subjects reflected the degree of mucus hyper-secretion. Interestingly, patients with CA showed negative correlations of mucin levels with respiratory resistance indices on impulse oscillation [34] and with airway sensitivity to methacholine [35], possibly indicating protective effects of airway-secreted mucin in asthma [32].

\section{COUGH VARIANT ASTHMA}

In CVA cough is the sole presenting symptom. CVA is characterized by AHR. It responds to bronchodilators such as beta-agonists and theophyllines [8, 19, 20]. In Japan, CVA remains the most common cause of chronic cough followed by SBS, GERD and AC [2, 19, 20, 36-38]. The 'health insurance for all' in Japan allow patients to visit a specialist without prior referral from a general practitioner. The patients in fact prefer to be assessed by a specialist [2]. In the majority of patients with CVA cough can be controlled with inhaled corticosteroids. General practitioners in Japan are less likely to prescribe inhaled corticosteroids than those in Western countries [39]. This may partially explain the high prevalence of CVA in Japan.

\section{ATOPIC FEATURES}

Seasonal variation of symptom is very common in CVA, which may implicate an involvement of atopy. We compared 74 CVA patients with $115 \mathrm{CA}$ patients with wheezing with regard to total and specific IgE levels of 7 common aeroallergens [40]. The two groups of asthmatics were sensitized to one or more allergens at a similar prevalence (60\% vs 67\%). However, patients with CA had higher total $\mathrm{IgE}$, larger numbers of sensitized allergens, and higher rates 
of sensitization to a number of allergens than did patients with CVA. The results revealed no specific antigen of CVA with higher sensitization rate than CA [40]. A literature review indicates that the prevalence of atopy in CVA, as defined by the presence of at least one positive serum specific IgE or skin test response to common aeroallergens, ranges from 40 to $80 \%[16,17,32,40-44]$.

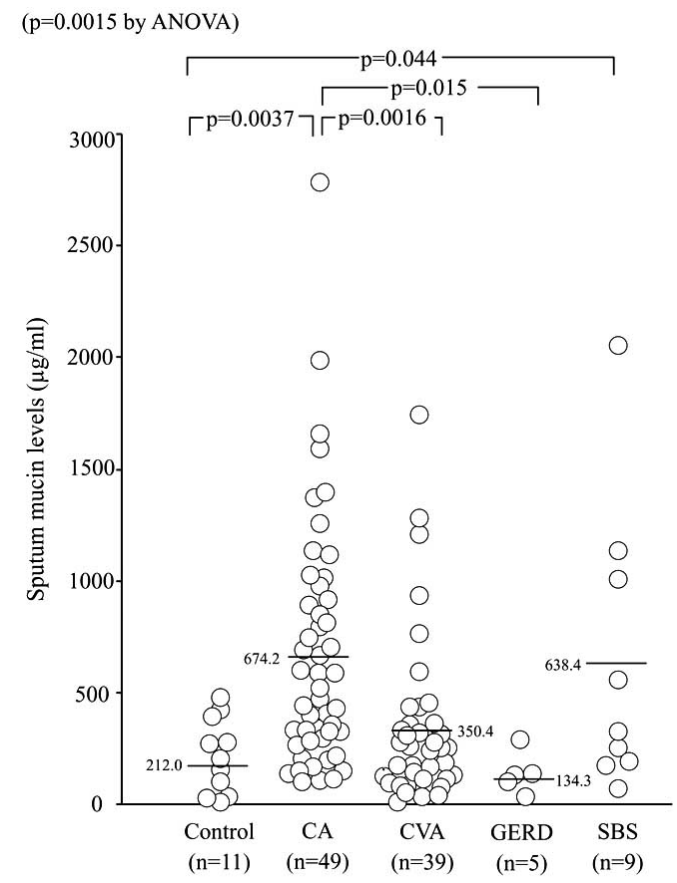

Fig. (2). Induced sputum levels of muciun in patients with asthma and chronic cough (ref. [32]).

\section{PHYSIOLOGICAL FEATURES}

Pulmonary function tests of CVA patients show normal to near normal results of peak expiratory flow (PEF) or $\mathrm{FEV}_{1}$, but when compared with healthy subjects or patients with post-infectious cough, these values may be slightly but significantly lower [41]. Mild diurnal change of PEF or its fluctuation in parallel with coughing may be observed [45], but to a lesser degree than that seen in CA. Reversibility of $\mathrm{FEV}_{1}$ with beta-agonist is smaller in CVA than in CA, because baseline $\mathrm{FEV}_{1}$ values are normal or nearly normal in the majority of CVA patients. In addition to these facts, CVA is the only cause of chronic cough that is responsive to bronchodilators $[5,46]$. It is thus suggested that coughing of CVA may be due to bronchoconstriction, but the detailed causal relationship involved in cough and bronchoconstriction remains unknown. A recent animal experiment has suggested that cough due to bronchoconstriction is mediated via rapidly adapting receptors, but not $\mathrm{C}$ fibers [47]. $(\mathrm{p}<0.0001$ by ANOVA)

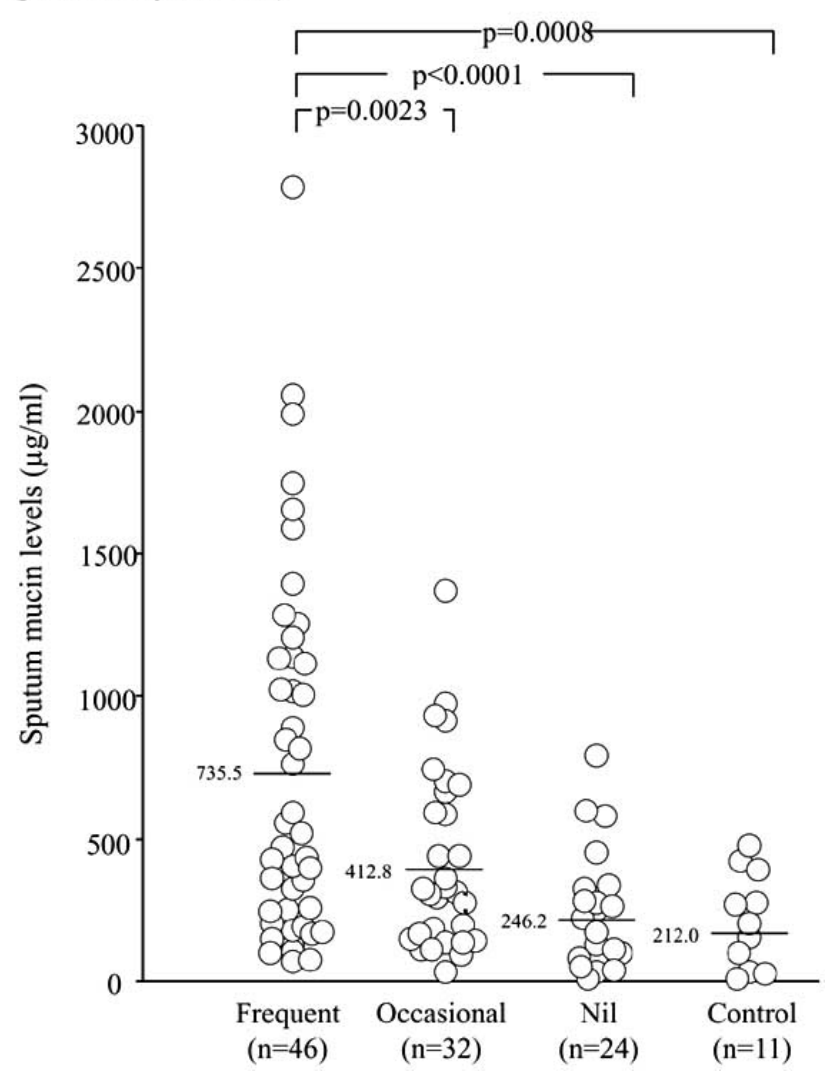

Fig. (3). Sputum mucin levels in patients of all disease groups reclassified according to their frequency of sputum production and in controls (ref. [32]).

AHR of CVA patients has been considered similar to or milder than that of CA patients. In adult CVA patients, airway sensitivity (threshold dose of methacholine to increase respiratory resistance) and airway reactivity (slope of methacholine - respiratory resistance dose response curve) of a tidal breathing method [35] were both smaller than in CA patients [48]. In children, only airway reactivity was smaller in CVA patients than in CA patients [49], possibly explaining the absence of wheezing in CVA. As a whole, the physiological abnormalities of CVA are more modest than those of CA. However, this does not mean that CVA is a milder form of asthma, because CVA patients are often more difficult to manage than CA patients who predominately present with wheeze. Cough receptor sensitivity, most commonly assessed by inhalation of capsaicin, may or may not be heightened in CVA as compared with healthy controls, and may decrease with treatment with leukotriene receptor antagonists [50] while remain unchanged with ICS treatment [51]. This might be associated with excellent antitussive effect of the former class of drugs [52], but the details of its mechanism remain unknown.

\section{PATHOLOGICAL FEATURES}

In patients with CVA, eosinophils are increased in the sputum [51, 53], bronchoalveolar lavage (BAL) fluid and bronchial mucosal tissue [41]. The magnitude of this 
increase correlates with the severity of disease as defined by symptom and treatment required to achieve control [41]. For biopsy specimens of central airway mucosa and BAL fluid recovered from peripheral airways and lung parenchyma, the degree of eosinophilia is similar between CA and CVA, indicating a similarity in the site of inflammation [41]. One study showed an increase of neutrophils as well as eosinophils in the airway mucosa of CVA patients (Fig. 4) [30], and such concomitant increase of both cells may lead to more severe disease characterized by refractoriness to treatment with ICS [54]. Mast cells, an important source of tussive as well as fibrogenic mediators, was increased in the airway mucosa of non-asthmatic chronic cough patients but not CVA patients (Fig. 4) [30].

Similar to asthma, in CVA structural changes such as sub-epithelial thickening, goblet cell hyperplasia and vascular proliferation have been demonstrated on mucosal biopsies $[30,55,56]$. These changes may be secondary to airway inflammation. Pathophysiological significance of these changes has been indicated in asthma, and early antiinflammatory treatment is also recommended in CVA. However, they may also be a consequence of long-term mechanical stimulation by coughing $[30,56,57]$, because most of these changes are also present in subjects with nonasthmatic chronic cough $[30,56]$. Increased inflammatory mediators (e.g. histamine, prostaglandins $D_{2}$ and $E_{2}$ and leukotrienes C4, D4 and E4) [23], increased expression of capsaicin receptor TRPV-1 [58], and decreased $\mathrm{pH}$ of airway lining fluid that may activate TRPV-1 [59] may play a role in the development of cough. One study showed a similar pattern of sputum markers (cellular and humoral) between CA and CVA [60]. A computed tomography (CT) study has
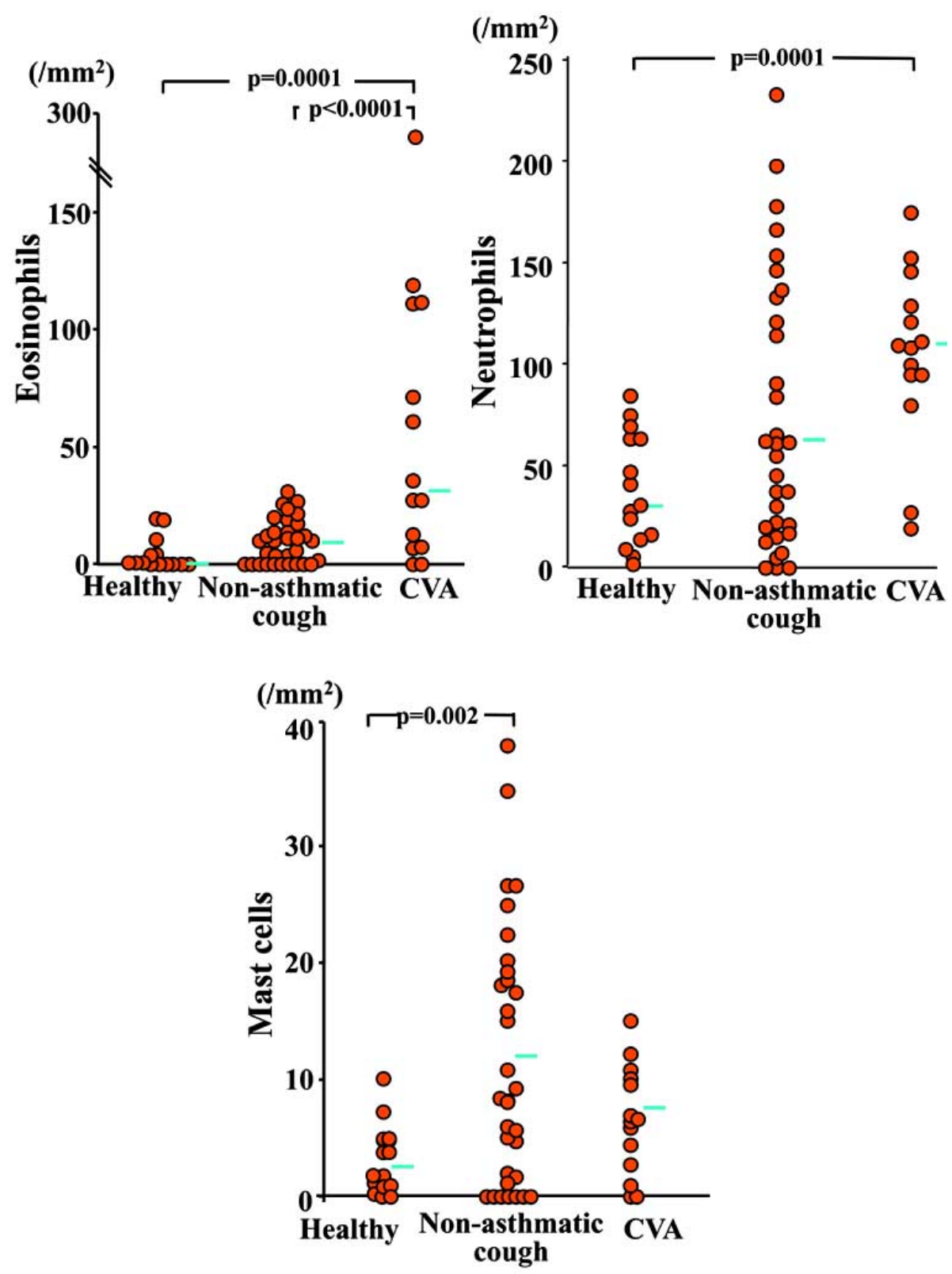

Fig. (4). Number of eosinophils, neutrophiils and mast cells in the submucosa of bronchial biopsy specimens obtained from patients with CVA ( $n=14)$, those with non-asthmatic chronic cough $(n=33 ; 6$ with postnasal drip/rhinitis, 5 with GERD, 3 with bronchiectasis, and 19 with idiopathic disease) and 15 healthy subjects [30]. 
revealed airway wall thickening, a feature of CA [61], in patients with CVA (Fig. 5a, b) [42]. This may reflect the net effect of airway remodeling features discussed above. However, airway wall thickening is also present in patients with non-asthmatic chronic cough although to a lesser degree (Fig. 5b) [42], which is consistent with the biopsy studies $[30,56]$.

\section{DIAGNOSIS}

CVA is characterized by AHR and responsiveness to bronchodilators, but the presence of AHR is only consistent with, but not diagnostic of, CVA [46]. Improvement of cough with bronchodilators such as beta-agonists is the essential diagnostic feature of CVA, as demonstrated by the double-blind controlled study by Irwin et al. [46]. Based on these features, the Japanese Respiratory Society cough guideline considers responsiveness to bronchodilators as the key diagnostic feature of CVA [5]. Sputum eosinophilia suggests a diagnosis of CVA [51, 53], as well as AC or NAEB. However, only $30 \%$ of CVA patients fulfill the criteria of sputum eosinophilia as defined by $>3 \%$ of leukocytes [14] in our experience (unpublished data), and its absence does not exclude the diagnosis of CVA. Exhaled NO levels may also be elevated and useful in the diagnosis of CVA [62].

\section{TREATMENT AND PROGNOSIS}

After the diagnosis is established, treatment of CVA is essentially the same as in CA [5]. Bronchodilators (shortacting inhaled $\beta_{2}$ agonists or theophyllines) may be used especially in patients with intermittent cough. However, as in CA eosinophilic airway inflammation and remodeling are present in CVA, ICS are the first line treatment in CVA especially in those patients who have persistent cough [30, $41,55,56]$. There are no data currently available regarding the choice of ICS, its dose or duration that should be used for the treatment of CVA $[3,52,63]$. If ICS mono-therapy is insufficient, other agents can be added such as long-acting $\beta_{2}$ agonists, slow-release theophylline, or leukotriene receptor antagonists [5]. Effectiveness of mono-therapy with leukotriene receptor antagonists has been reported possibly through its anti-inflammatory effects [50, 64]. Occasionally,

(a)

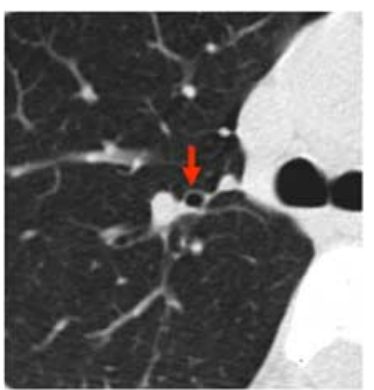

Healthy

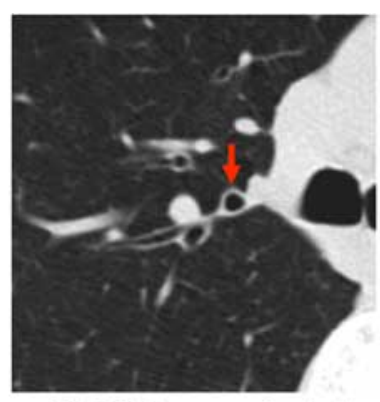

GERD-associated cough

(b)

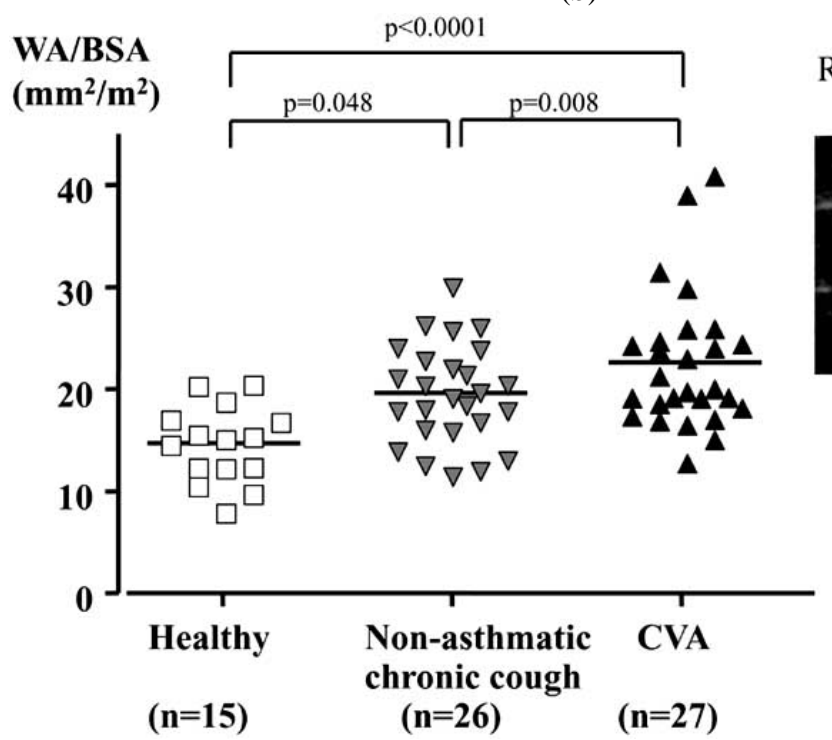

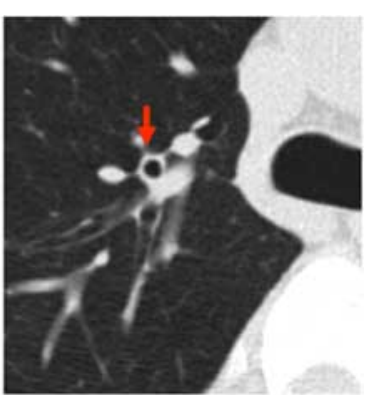

Cough variant asthma

Right apical upper lobe bronchus

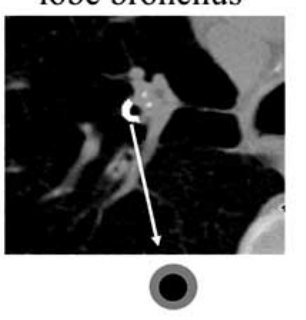

\section{Wall Area (WA)}

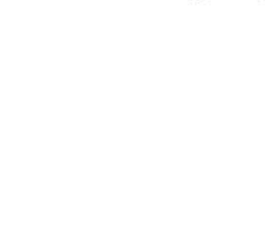

Fig. (5). Airway wall thickening in patients with CVA $(n=27)$ and non-asthmatic chronic cough ( $n=26 ; 8$ with SBS, 3 with GERD, 3 with post-infective cough, 11 with unexplained cough, and 1 with combined SBS and GERD), as indicate by helical CT scans of right apical upper lobe bronchus (a). Airway wall thickness (wall area/body surface area) as quantified by automatic analysis shows that airway walls of patients are thickened as compared with healthy subjects $(n=15)$, to a greater degree in patients with CVA (b) [42]. 
Table 1. Clinical and Pathological Features of Eosinophilic Airway Disorders

\begin{tabular}{|c|c|c|c|c|}
\hline & Classic Asthma & CVA & NAEB & $\mathbf{A C}$ \\
\hline Symptoms & Cough, SOB, wheeze & Cough only & Cough (often with upper airway symptoms) & Cough only \\
\hline Atopy* & $60-80 \%$ & $40-80 \%$ & $20-70 \%$ & $40-50 \%$ \\
\hline Variable airflow limitation & + & \pm & - & - \\
\hline AHR & + & + & - & - \\
\hline Cough hypersensitivity & $-\sim \uparrow$ & $-\sim \uparrow$ & $\uparrow$ & $\uparrow$ \\
\hline Response to bronchodilator & + & + & unknown & - \\
\hline Response to corticosteroid & + & + & + & + \\
\hline Response to $\mathrm{H}_{1}$ antagonists & \pm & \pm & unknown & + \\
\hline Rapid decline of lung function & + & \pm & \pm & - \\
\hline Progression to classic asthma & NA & $30 \%$ & $10 \%$ & rare \\
\hline Sputum $\operatorname{eos} \uparrow(>3 \%)$ & usually & usually & always (by definition) & usually \\
\hline Exhaled NO & $\uparrow$ & $\uparrow$ & $\uparrow$ & $\rightarrow$ \\
\hline Submucosal eos & $\uparrow$ & $\uparrow$ & $\uparrow$ & $\uparrow$ \\
\hline BAL eos & $\uparrow$ & $\uparrow$ & $\uparrow$ & $\rightarrow$ \\
\hline Mast cells in ASM & $\uparrow$ & $\rightarrow$ & $\rightarrow$ & unknown \\
\hline Subepithelial thickening & + & + & + & unknown \\
\hline Vascular proliferation & + & + & + & unknown \\
\hline
\end{tabular}

*Defined by the presence of at least one positive serum specific IgE or skin test response to common aeroallergens.

for acute exacerbations of CVA, a short-course of oral corticosteroids may be required. A subset of patients with CVA can develop wheeze and progresses to CA. If ICS are not used in CVA, the progression rate to $\mathrm{CA}$ has been reported between 30 to $40 \%[17,43]$. Factors that may predict the development of CA include AHR [17] and exaggerated maximal airway response to methacholine, sputum eosinophilia [65], and sensitization to allergens [40]. Early ICS treatment may reduce the risk of progression to CA $[17,43]$. Avoidance of relevant allergens might also be important [40]. As in CA cough in CVA often re-occurs if treatment is discontinued [43].

Annual changes of $\mathrm{FEV}_{1}$ have been reported to be similar among patients with CVA (-29 ml/year by average), those with AC (-21 ml/year) and healthy subjects $(-28 \mathrm{ml} / \mathrm{yr})$. Values for CVA patients ranged from approximately $-90 \mathrm{ml}$ to $+30 \mathrm{ml}$ [18]. In our 3- year follow-up [19], annual changes of $\mathrm{FEV}_{1}$ were $-2 \pm 36 \mathrm{ml}$ in 7 patients with mild CVA (coughing episodes interfering with usual activities or sleep 3 times or less yearly), and $-62 \pm 35 \mathrm{ml}$ in 4 patients with difficult-to-control disease ( 4 or more such episodes yearly) $(\mathrm{p}=0.014)$. The difficult-to-control group was treated with higher doses of ICS than the mild group, reflecting their severity [19]. Although this is a small study, these results may be consistent with recent studies in CA that showed a positive relationship between the number of asthma exacerbations and progressive loss of $\mathrm{FEV}_{1}$ [66].

\section{DISORDERS RELATED TO CVA}

Atopic cough as proposed by Fujimura et al. [16-18, 44, 51] presents with bronchodilator-resistant dry cough associated with an atopic constitution. It is characterized by eosinophilic tracheobronchitis and cough hypersensitivity. However, there is absence of AHR and variable airflow obstruction. AC usually responds to ICS treatment. These features are shared by NAEB [13-15, 53]. However, AC lacks BAL eosinophilia [16]. Unlike CVA [17, 41, 43, 44] and NAEB [19, 67, 68], AC rarely progresses to $\mathrm{CA}$ with wheezing [17]. Histamine $\mathrm{H}_{1}$ antagonists are effective in AC [69], but their efficacy in NAEB is unknown. The involvement of airway remodeling and accelerated decline of lung funciton, which has been shown in CVA [19, 30, 42, 55] and NAEB [15, 70, 71], is unknown for AC. NAEB thus significantly overlaps with AC, but might also include milder cases of CVA with very modest AHR. The clinical and pathological features of eosinophilic airway disorders including CA are summarized in Table $\mathbf{1}$. The confusion, or lack of consensus, in these related entities may be affecting the etiology of chronic cough reported from various countries [2, 19].

\section{CONCLUSIONS}

CVA is one of the most common causes of chronic cough. CVA therefore should be considered in patients presenting with persistent cough. The role of inhaled corticosteroids in CVA is very important. The inhaled corticosteroids not only control cough in CVA but also they may prevent the development of wheeze, airway remodeling and chronic airflow obstruction.

\section{REFERENCES}

[1] American College of Chest Physicians. Diagnosis and management of cough: ACCP evidence-based clinical practice guidelines. Chest 2006; 129: 1S-292S.

[2] Niimi A. Geography and cough aetiology. Pulm Pharmacol Ther 2007; 20: 383-7. 
[3] Morice AH and committee members. ERS Task Force. The diagnosis and management of chronic cough. Eur Respir J 2004; 24: 481-92.

[4] Morice AH, McGarvey L, Pavord I; British Thoracic Society Cough Guideline Group. Recommendations for the management of cough in adults. Thorax 2006; 61(Suppl 1): i1-24.

[5] Committee for the Japanese Respiratory Society Guidelines for Management of Cough; Kohno S, Ishida T, Uchida Y, et al. The Japanese Respiratory Society guidelines for management of cough. Respirology 2006; 11(Suppl 4): S135-86.

[6] Birring SS, Prudon B, Carr AJ, Singh SJ, Morgan MD, Pavord ID. Development of a symptom specific health status measure for patients with chronic cough: Leicester Cough Questionnaire (LCQ). Thorax 2003; 58: 339-43.

[7] Glauser FL. Variant asthma. Ann Allergy 1972; 30: 457-9.

[8] Corrao WM, Braman SS, Irwin RS. Chronic cough as the sole presenting manifestation of bronchial asthma. N Engl J Med 1979; 300: 633-7.

[9] Chung KF, Pavord ID. Prevalence, pathogenesis, and causes of chronic cough. Lancet. 2008; 19; 371(9621): 1364-74.

[10] Manfreda MR, Becklake MR, Sears M, et al. Prevalence of asthma symptoms among adults aged 20-44 years in Canada, CMAJ 2001; 164: 995-1001.

[11] de Marco RA, Marcon D, Jarvis D, et al. Prognostic factors of asthma severity: a 9-year international prospective cohort study, J Allergy Clin Immunol 2006; 117: 1249-56.

[12] Osman LM, McKenzie J, Cairns, J, et al. Patient weighting of importance of asthma symptoms. Thorax 2001; 56: 138-42.

[13] Gibson PG, Dolovich J, Denburg J, Ramsdale EH, Hargreave FE. Chronic cough: eosinophilic bronchitis without asthma. Lancet 1989; 1: 1346-8.

[14] Brightling CE, Ward R, Goh KL, et al. Eosinophilic bronchitis is an important cause of chronic cough. Am J Respir Crit Care Med 1999; 160: 406-10.

[15] Brightling CE, Bradding P, Symon FA, et al. Mast cell infiltration of airway smooth muscle in asthma. N Engl J Med 2002; 346: 1699-705.

[16] Fujimura M, Ogawa H, Yasui M, Matsuda T. Eosinophilic tracheobronchitis and airway cough hypersensitivity in chronic non-productive cough. Clin Exp Allergy 2000; 30: 41-7.

[17] Fujimura M, Ogawa H, Nishizawa Y, Nishi K. Comparison of atopic cough with cough variant asthma: is atopic cough a precursor of asthma? Thorax 2003; 58: 14-8.

[18] Fujimura M, Nishizawa Y, Nishitsuji M et al. Longitudinal decline in pulmonary function in atopic cough and cough variant asthma. Clin Exp Allergy 2003; 33: 588-94.

[19] Niimi A, Matsumoto H, Mishima M. Eosinophilic airway disorders associated with chronic cough. Pulm Pharmacol Ther 2009; 22: 114-20.

[20] Niimi A. Cough variant asthma: a major cause of chronic cough. Clin Pulm Med 2008; 15: 189-96.

[21] Lalloo UG, Barnes PJ, Chung KF. Pathophysiology and clinical presentations of cough. J Allergy Clin Immunol 1996; 98: S91-6.

[22] Xiang A, Uchida Y, Nomura A, et al. Involvement of thromboxane $\mathrm{A}(2)$ in airway mucous cells in asthma-related cough. J Appl Physiol 2002; 92: 763-70.

[23] Birring SS, Parker D, Brightling CE, et al. Induced sputum inflammatory mediator concentrations in chronic cough. Am J Respir Crit Care Med 2004; 169: 15-9.

[24] Jinnai M, Niimi A, Takemura M, et al. Gastroesophageal refluxassociated chronic cough in an adolescent and the diagnostic implications: a case report. Cough 2008; 4: 5.

[25] Ing AJ. Cough and gastro-oesophageal reflux disease. Pulm Pharmacol Ther 2004; 17: 403-13.

[26] Marsden PA', Smith JA, Kelsall AA, et al. A comparison of objective and subjective measures of cough in asthma. J Allergy Clin Immunol 2008; 122: 5903-7.

[27] Ulrik CS. Outcome of asthma: longitudinal changes in lung function. Eur Respir J 1999; 13: 904-18.

[28] Kuyper LM, Paré PD, Hogg JC, et al. Characterization of airway plugging in fatal asthma. Am J Med 2003; 115: 6-11.

[29] Ordoñez C, Khashayar R, Wong H, et al. Mild and moderate asthma is associated with airway goblet cell hyperplasia and abnormalities in mucin gene expression. Am J Respir Crit Care Med 2001; 163: 517-23.
[30] Niimi A, Torrego A, Nicholson A, et al. Nature of airway inflammation and remodeling in chronic cough. J Allergy Clin Immunol 2005; 116: 565-70.

[31] Smyrnios NA, Irwin RS, Curley FJ. Chronic cough with a history of excessive sputum production. The spectrum and frequency of causes, key components of the diagnostic evaluation, and outcome of specific therapy. Chest 1995; 108: 991-7.

[32] Jinnai M, Niimi A, Ueda T, et al. Induced sputum concentrations of mucin in patients with asthma and chronic cough. Chest 2010;137: 1122-9.

[33] Matsuoka H, Niimi A, Matsumoto H, et al. Patients' characteristics associated with unsuccessful sputum induction in asthma. J Allergy Clin Immunol 2008; 121: 774-6.

[34] Yamaguchi M, Niimi A, Ueda T, et al. Effect of inhaled corticosteroids on small airways in asthma: investigation using impulse oscillometry. Pulm Pharmacol Ther 2009; 22: 326-32.

[35] Niimi A, Matsumoto H, Takemura M, et al. Relationship of airway wall thickness to airway sensitivity and airway reactivity in asthma. Am J Respir Crit Care Med 2003; 168: 983-8.

[36] Shirahata K, Fujimoto K, Arioka H, Shouda R, Kudo K, Ikeda S Prevalence and clinical features of cough variant asthma in a general internal medicine outpatient clinic in Japan. Respirology 2005; 10: 354-8.

[37] Fujimura M, Abo M, Ogawa H, et al. Importance of atopic cough, cough variant asthma and sinobronchial syndrome as causes of chronic cough in the Hokuriku area of Japan. Respirology 2005; 10: 201-7.

[38] Matsumoto H, Niimi A, Takemura M, et al. Prevalence and clinical manifestations of gastro-oesophageal reflux-associated chronic cough in the Japanese population. Cough 2007; 8: 3:1

[39] Rabe KF, Adachi M, Lai CK, et al. Worldwide severity and control of asthma in children and adults: the global asthma insights and reality surveys. J Allergy Clin Immunol 2004; 114: 40-7.

[40] Takemura M, Niimi A, Matsumoto H, et al. Atopic features of cough variant asthma and classic asthma with wheezing. Clin Exp Allergy 2007; 37: 1833-939.

[41] Niimi A, Amitani R, Suzuki K, Tanaka E, Murayama T, Kuze F. Eosinophilic inflammation in cough variant asthma. Eur Respir J 1998; 11: 1064-9.

[42] Matsumoto H, Niimi A, Tabuena R, et al. Airway wall thickening in patients with cough variant asthma and nonasthmatic chronic cough. Chest 2007; 131: 1042-9.

[43] Matsumoto H, Niimi A, Takemura M, et al. Prognosis of cough variant asthma: a retrospective analysis. J Asthma 2006; 43: 131-5.

[44] Fujimura M, Kamio Y, Hashimoto $\mathrm{T}$, et al. Cough receptor sensitivity and bronchial responsiveness in patients with only chronic nonproductive cough: in view of effect of bronchodilator therapy. J Asthma 1994; 31: 463-72.

[45] Sano T, Ueda H, Bando H. A preliminary study of PEFR monitoring in patients with chronic cough. Lung 2004; 182: 28595

[46] Irwin RS, French CT, Smyrnios NA, et al. Interpretation of positive results of a methacholine inhalation challenge and 1 week of inhaled bronchodilator use in diagnosing and treating cough-variant asthma. Arch Intern Med 1997; 157: 1981-7.

[47] Ohkura N, Fujimura M, Hara J, et al. Bronchoconstrictiontriggered cough in conscious guinea pigs. Exp Lung Res 2009; 35 296-306.

[48] Matsumoto H, Niimi A, Takemura M, et al. Features of cough variant asthma and classic asthma during methacholine-induced brochoconstriction: a cross-sectional study. Cough 2009; 9: 5:3.

[49] Mochizuki H, Arakawa H, Tokuyama $\mathrm{K}$, et al. Bronchial sensitivity and bronchial reactivity in children with cough variant asthma. Chest 2005; 128: 2427-34.

[50] Dicpinigaitis PV, Dobkin JB, Reichel J. Antitussive effect of the leukotriene receptor antagonist zafirlukast in subjects with coughvariant asthma. J Asthma 2002; 39: 291-7.

[51] Fujimura M, Songür N, Kamio Y, Matsuda T. Detection of eosinophils in hypertonic saline-induced sputum in patients with chronic nonproductive cough. J Asthma 1997; 34: 119-26.

[52] Dicpinigaitis PV. Chronic cough due to asthma: ACCP evidencebased clinical practice guidelines. Chest 2006; 129(1 Suppl): $75 \mathrm{~S}$ $79 \mathrm{~S}$.

[53] Gibson PG, Fujimura M, Niimi A. Eosinophilic bronchitis: clinical manifestations and implications for treatment. Thorax 2002; 57: 178-82. 
[54] Matsuoka H, Niimi A, Matsumoto $\mathrm{H}$, et al. Inflammatory subtypes in cough variant asthma: Association with maintenance doses of inhaled corticosteroids. Chest 2010; [Epub ahead of print].

[55] Niimi A, Matsumoto H, Minakuchi M, Kitaichi M, Amitani R. Airway remodelling in cough-variant asthma. Lancet 2000; 356: 564-5.

[56] Irwin RS, Ownbey R, Cagle PT, Baker S, Fraire AE. Interpreting the histopathology of chronic cough: a prospective, controlled, comparative study. Chest 2006; 130: 362-70.

[57] Niimi A, Chung KF. Airway inflammation and remodelling changes in patients with chronic cough: do they tell us about the cause of cough? Pulm Pharmacol Ther 2004; 17: 441-6.

[58] Groneberg DA, Niimi A, Dinh Q-T, et al. Increased expression of transient receptor vanilloid-1 in airway nerves of chronic cough. Am J Respir Crit Care Med 2004; 170: 1276-80.

[59] Niimi A, Nguyen LT, Usmani O, Mann BS, Chung KF. Reduced $\mathrm{pH}$ and chloride levels in exhaled breath condensate of patients with chronic cough. Thorax 2004; 59: 608-12.

[60] De Diego A, Martínez E, Perpiñá M, et al. Airway inflammation and cough sensitivity in cough-variant asthma. Allergy 2005; 60: 1407-11.

[61] Niimi A, Matsumoto H, Amitani R, et al. Airway wall thickness in asthma assessed by computed tomography. Relation to clinical indices. Am J Respir Crit Care Med 2000; 162: 1518-23.

[62] Chatkin JM, Ansarin K, Silkoff PE, et al. Exhaled nitric oxide as a noninvasive assessment of chronic cough. Am J Respir Crit Care Med 1999; 159: 1810-3.
[63] Engel T, Heinig JH, Malling HJ, Scharling B, Nikander K, Madsen F. Clinical comparison of inhaled budesonide delivered either via pressurized metered dose inhaler or Turbuhaler. Allergy 1989; 44: $220-5$.

[64] Spector SL, Tan RA. Effectiveness of montelukast in the treatment of cough variant asthma. Ann Allergy Asthma Immunol 2004; 93: 232-6.

[65] Kim CK, Kim JT, Kang H, et al. Sputum eosinophilia in coughvariant asthma as a predictor of the subsequent development of classic asthma. Clin Exp Allergy 2003; 33: 1409-14.

[66] Bai TR, Vonk JM, Postma DS, Boezen HM. Severe exacerbations predict excess lung function decline in asthma. Eur Respir J 2007; 30: 452-6.

[67] Berry MA, Hargadon B, McKenna S, et al. Observational study of the natural history of eosinophilic bronchitis. Clin Exp Allergy 2005; 35: 598-601

[68] Hancox RJ, Leigh R, Kelly MM, Hargreave FE. Eosinophilic bronchitis. Lancet 2001; 358: 1104.

[69] Shioya T, Satake M, Kagaya M, et al. Antitussive effect of the selective $\mathrm{H}_{1}$ antagonist epinastine in the patients with atopic cough (eosinophilic bronchitis). Arzneimittelforshung/Drug Res 2004; 54: 207-12.

[70] Siddiqui S, Sutcliffe A, Shikotra A, et al. Vascular remodeling is a feature of asthma and nonasthmatic eosinophilic bronchitis. J Allergy Clin Immunol 2007; 120: 813-9.

[71] Park SW, Lee YM, Jang AS, et al. Development of chronic airway obstruction in patients with eosinophilic bronchitis: a prospective follow-up study. Chest 2004; 125: 1998-2004. 